Research Article

\title{
Effects of the Rock Bridge Ligament on Fracture and Energy Evolution of Preflawed Granite Exposed to Dynamic Loads
}

\author{
Kaihua Sun $\mathbb{D}^{1,2}$ Xiong Wu, ${ }^{1}$ Xuefeng $Y i^{3}$ and Yu Wang $\mathbb{D}^{3}$ \\ ${ }^{1}$ School of Water Resources and Environment, China University of Geosciences (Beijing), Beijing 100083, China \\ ${ }^{2}$ CCTEG Ecological Environment Technology Co., Ltd., Beijing 100013, China \\ ${ }^{3}$ Beijing Key Laboratory of Urban Underground Space Engineering, Department of Civil Engineering, \\ School of Civil \& Resource Engineering, University of Science \& Technology Beijing, Beijing 100083, China \\ Correspondence should be addressed to Yu Wang; wyzhou@ustb.edu.cn
}

Received 29 August 2021; Accepted 20 September 2021; Published 5 October 2021

Academic Editor: Gan Feng

Copyright (c) 2021 Kaihua Sun et al. This is an open access article distributed under the Creative Commons Attribution License, which permits unrestricted use, distribution, and reproduction in any medium, provided the original work is properly cited.

\begin{abstract}
This paper aims to reveal the mechanical properties, energy evolution characteristics, and dynamic rupture process of preflawed granite under impact loading with different rock bridge angles and strain rates. A series of dynamic impact experiments were conducted along with the separate Hopkinson press bar (SHPB) testing system to analyze and study the overall rock fracture process. Under the impact load, the peak stress of granite increases with the increase of rock bridge angle and strain rate, but the increase gradually decreases. The peak strain also increases gradually with the increase of rock bridge angle, but there is an upper limit value; the total input strain energy increases with the increase of strain rate and rock bridge angle. It is shown that the higher the strain rate, the higher the unit dissipation energy, and the greater the degree of rock fragmentation. For rock under impact loads, the crack first initiates from the wing end of the prefabricated flaw, the preflaw closes gradually, and finally the crack propagates at the locking section leading to the coalescence of rock bridge. With the increase of strain rate, the fragmentation degree of the specimen increases asymptotically, and the average fragmentation size of the specimen decreases with the increase of strain rate. It is suggested that the stability of large rocked slopes is controlled by the locked section, and understanding the fracture evolution of the rock bridge is the key to slope instability prediction.
\end{abstract}

\section{Introduction}

In the current mining process, blasting is an important means of extraction, and along with the effects of exiting, excavation, and blasting operations, the rock masses in the open pit slope are disturbed by dynamic loads to varying degrees; therefore, it is particularly necessary to reveal the influence of impact dynamics on rock instability [1-3]. The natural fractures in the mine rock are not continuous, and the discontinuous fractures form a kind of rock bridges (i.e., rock-locked sections) $[4,5]$. The stress conditions at rock bridges are often more complex due to the greater shear stresses, and the presence of rock bridges can increase the strength of the weak surfaces of the rock mass, which is called the locking effect of rock bridges on intermittent jointed rock masses $[6,7]$. The fracture of rock bridges leads to the connection of joints, and destabilization damage will occur only when all rock bodies are connected by the previous fractures [8]. Therefore, the fracture mechanism of rock bridges needs to be studied to ensure the stability of rock masses in open pit mines and the safety of mining.

The impact loading testing is different from the conventional static loading and cyclic loading tests. Usually, the impact loading testing is applied high strain rate on rock, which is different from the medium-low strain rate of the cyclic or fatigue loading conditions [9-13]. The properties of rock bridge and the current status of slope instability have been widely studied by scholars worldwide. Yin et al. [9] used split Hopkinson pressure bar and high-speed digital image correlation (DIC) technology to investigate the fullfield deformation characteristics of phyllite under Brazilian disc test. Wong et al. [14] studied the cracking process and 
strength characteristics of rock-like fracture materials with different flaw inclination angles, different inclination of rock bridges, and different frictional characteristics of the crack contact surface by uniaxial compression tests. Gomez et al. [15] used a high-speed camera to take photoelastic pictures of the specimen in dynamic BD test, where the specimen was subjected to impact loading, and after about 30us of stress wave propagation, the specimen reached stress equilibrium at both ends, and its internal stress state was consistent with the internal stress state of the specimen in quasi-static condition. Zhang and Zhao [16] combined SEM scanner, high-speed camera, DIC high-speed photography, and SHPB device to reproduce the whole process of rock surface impact damage by multiple means simultaneously. Li et al. [17] proposed a test method for dynamic compression strength of rocks under prestatic load and measured the dynamic compression strength of sandstone under preload, and the results showed that the dynamic compression strength of the specimen under preload was higher than its compression strength under pure static load or pure dynamic load. Gong et al. [18] found that the dissipation energy increased linearly with the increase of incident energy by conducting SHPB tests, and the linear energy dissipation law in dynamic compression tests was confirmed by connecting two different inclined paths by a critical incident energy. Yang et al. [19] conducted impact compression tests on samples of red sandstone, gray sandstone, and granite, which are common in rock engineering, with different impact velocities. The impact compression test of these three types of rocks was conducted to compare the stress wave propagation characteristics, dynamic stress-strain relationship, degree of fragmentation, and energy dissipation law. Wang et al. [20] investigated the mechanical properties and energy dissipation law of sandstone under impact loading and explored the change law under different temperature conditions.

Currently, most of the studies on the mechanical properties of jointed rocks are conducted by means of static loading tests; in addition, most of the studies on the characteristics of jointed rock masses under impact dynamic loading are focused on intact rock. The damage and fracture mechanism of the preflawed rock subjected to dynamic impacting loads are not well understood. Therefore, in order to reveal the effects of different joint angles and strain rates on the dynamic response of rock materials, SHPB impact testing was conducted on fissure-prefabricated specimens with different angles to analyze the effects of different joint angles and strain rates on the dynamic stress-strain analysis, energy evolution, and dynamic fracturing process.

\section{Test Materials and Methods}

2.1. Specimen Preparation. The test material was obtained from a metal mining at Western of China. According to $\mathrm{XRD}$ analysis, the granite is mainly composed of sodium feldspar, quartz, magnesia hornblende, orthoclase, and black mica, and the specific composition is shown in Figure 1. SEM imaging was performed on different granite specimens, and the SEM morphology of the specimens is shown in
Figure 2. The SEM imaging analysis shows that microcracks, pores, and mineral interfaces were distributed within rock.

Referring to the suggested method by ISRM for impact tests, the rock cores were drilled into cylindrical shape with a diameter $(D)$ of $50 \mathrm{~mm}$ and a height $(H)$ of $50 \mathrm{~mm}$ [21]. The granite specimens were prepared by polishing the ends of the specimens to ensure that the error of unevenness in the granite specimens was less than $0.05 \mathrm{~mm}$, and the error of parallelism at both ends was less than $0.1 \mathrm{~mm}$. In order to simulate the locking effect of the rock, double prefabricated fractures were prepared in the specimen by using waterjet cutting method, and two prefabricated fractures with $1 \mathrm{~mm}$ pore size were cut by spraying high-pressure water mixed with abrasive from a $0.75 \mathrm{~mm}$ diameter nozzle. As shown in Figure 3, the rock specimen contains oblique and horizontal fissures with a length of $8 \mathrm{~mm}$, the angles of approach of the oblique fissures are $30^{\circ}, 50^{\circ}$, and $70^{\circ}$, and the length of the locking section is set to $12 \mathrm{~mm}$.

2.2. Test Apparatus. The impact test was done on a separated Hopkinson pressure bar (SHPB) test system to determine the dynamic stress-strain, stress-time, and strain-time relationships of rock specimens under impact loading and to carry out an in-depth study of dynamic intrinsic relationships based on this. As shown in Figure 4, the SHPB device consists of a power system, an impact rod (bullet), an input rod, an output rod, an absorption rod, and a measurement recording system, with the tested specimen sandwiched between the input and output rods and auxiliary equipment: a super dynamic strain gauge, a transient waveform recorder, a computer, strain gauges, bullet velocity tests, and other devices.

The rock specimens were tested with different impact strain rates of $0.07,0.09,0.10$, and $0.11 \mathrm{MPa}$, and the average strain rates of the rocks corresponding to different impact pressures were $31.4 \mathrm{~s}^{-1}, 53.3 \mathrm{~s}^{-1}, 78.4 \mathrm{~s}^{-1}$, and $143.8 \mathrm{~s}^{-1}$. The test data were collected with the help of DHDAS dynamic signal acquisition system, and 30,000-frame high-speed camera was used to capture the rock crack extension process. The whole test process is shown in Figure 4.

2.3. Test Idea. The SHPB experiment is that the impacting rod strikes the input rod along the axial direction with a certain speed and generates a compressive stress wave in the input rod. The initial pressure pulse is reflected and simultaneously turned into a tension pulse by the free end of the pulse, and then the jet is directed to the opposite polarized light. Thus, the wavelength produced in the falling beam is the length of the projection. When the stress wave falling into the drop bar reaches the sample, due to changes in intermediate conditions, part of the drop stress wave crossing the interface is reflected on the drop bar and forms a reflected stress wave, while the other part of the stress wave passing through the sample and transmitted forms a transmitted and then transmitted stress wave that is "intercepted" by the absorber bar and eventually absorbed by the dynamic absorber or lining device. The "stress-strain signals" of the incident, reflected, and transmitted stress 


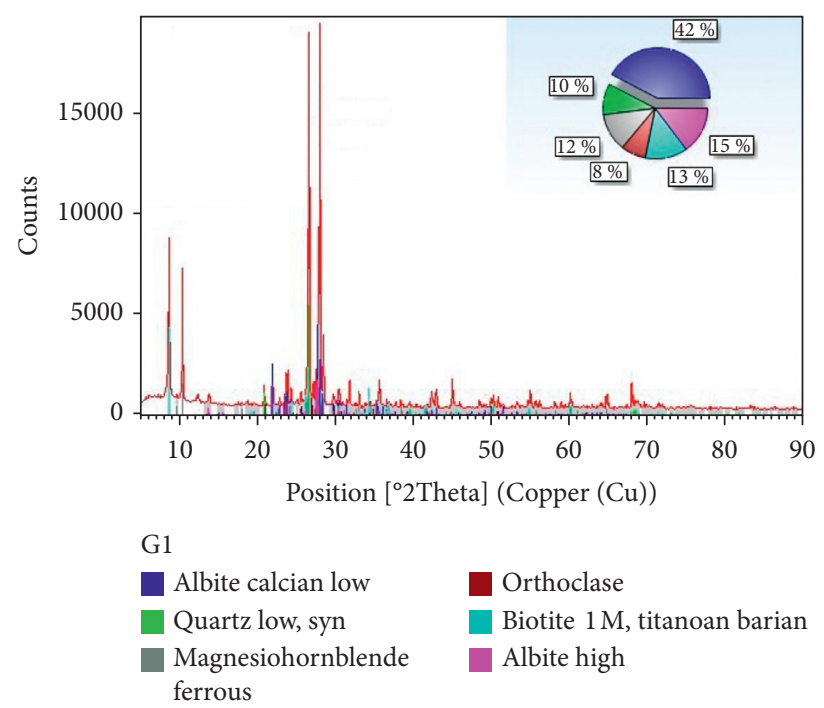

Figure 1: Mineral composition analysis using XRD method for the granite samples.

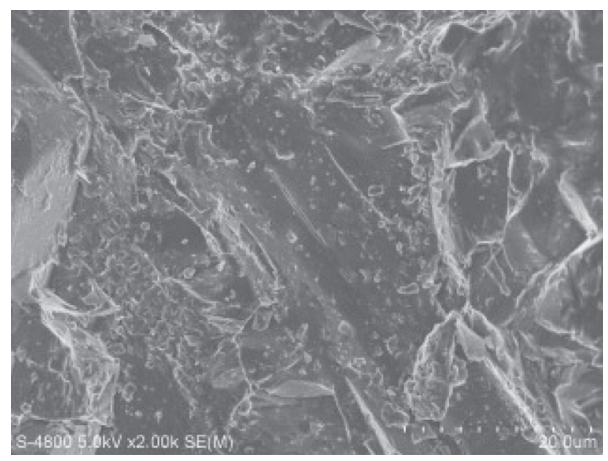

FIGURE 2: SEM results of rock specimens to observe its mesoscopic structure.

waves can be accurately recorded by using resistive strain gauges attached to the incident and transmitted rods, which makes it easy to determine the dynamic loads and displacements on both ends of the sample, and to derive the stress-strain relationships of the material $[22,23]$.

The basic principle of SHPB experiments is the theory of elastic stress waves in slender rods. According to the theory of stress wave propagation and the assumption of one-dimensional stress, and in accordance with the incoming type requirement of the displacement, the equations can be obtained as follows [24, 25]:

$$
\begin{aligned}
& u_{1}=C_{0} \varepsilon_{i} \int_{0}^{t} \mathrm{~d} \tau+\left(-C_{0}\right) \varepsilon_{r} \int_{0}^{t} \mathrm{~d} \tau, \\
& F_{1}=E A\left(\varepsilon_{i}+\varepsilon_{r}\right), \\
& u_{2}=C_{0} \varepsilon_{t} \int_{0}^{t} \mathrm{~d} \tau, \\
& F_{2}=E A \varepsilon_{T},
\end{aligned}
$$

where $u_{1}$ and $u_{2}$ are the cross-sectional displacements of the incident and transmitted rods in contact with the specimen, respectively; $C_{0}$ is the elastic longitudinal wave velocity of the waveguide rod; $F_{1}$ and $F_{2}$ are the forces acting on the two ends of the specimen, respectively; $E$ is the elastic modulus of the waveguide rod; and $A$ is the cross-sectional area of the waveguide rod.

From the above two equations, the strain $\varepsilon_{s}$, strain rate $\varepsilon_{s}$, and stress $\sigma_{s}$ on the specimen can be introduced as follows:

$$
\begin{aligned}
\sigma_{s} & =\frac{F_{1}+F_{2}}{2 A_{s}}\left(\varepsilon_{i}+\varepsilon_{r}+\varepsilon_{t}\right), \\
\varepsilon_{s} & =\frac{u_{1}-u_{1}}{l_{s}} \frac{C_{0}}{l_{s}} \int_{0}^{t}\left(\varepsilon_{i}-\varepsilon_{r}-\varepsilon_{t}\right) \mathrm{d} \tau, \\
\dot{\varepsilon}_{s} & =\frac{\mathrm{d} \varepsilon_{s}}{\mathrm{~d} t} \\
& =\frac{C_{0}}{l_{s}}\left(\varepsilon_{i}-\varepsilon_{r}-\varepsilon_{t}\right),
\end{aligned}
$$

where $l_{s}$ is the length of the specimen and $A_{s}$ is the crosssectional area of the specimen. According to the specimen stress uniformity assumption, we have $F_{1}=F_{2}$, and according to the one-dimensional stress wave theory, we have 


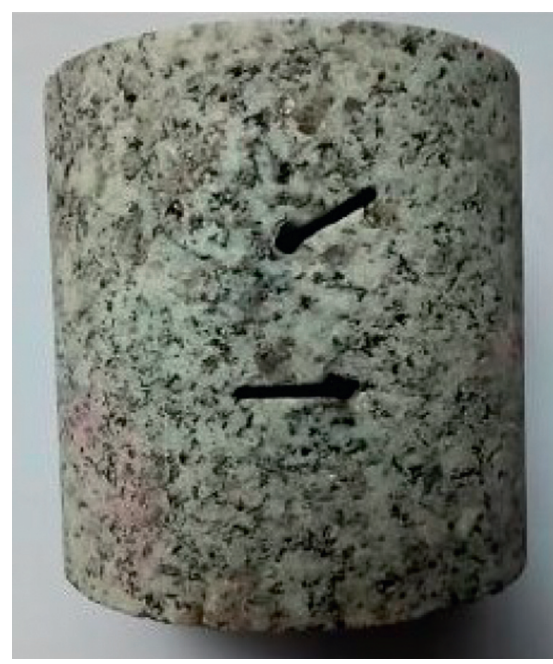

(a)

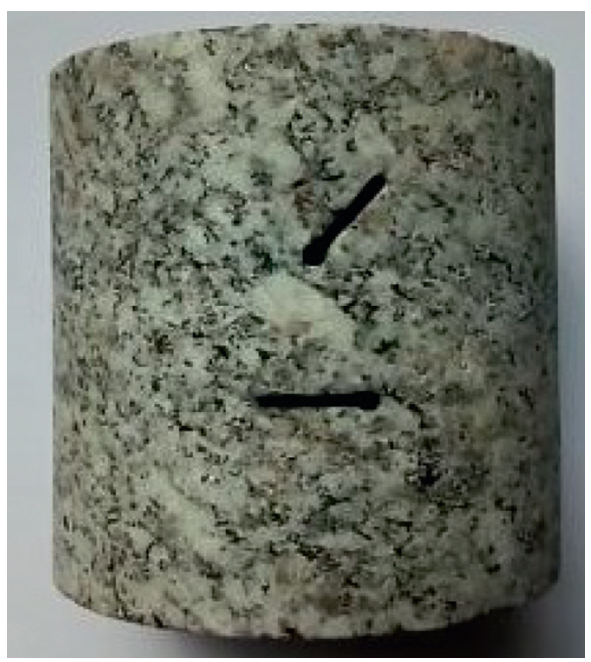

(b)

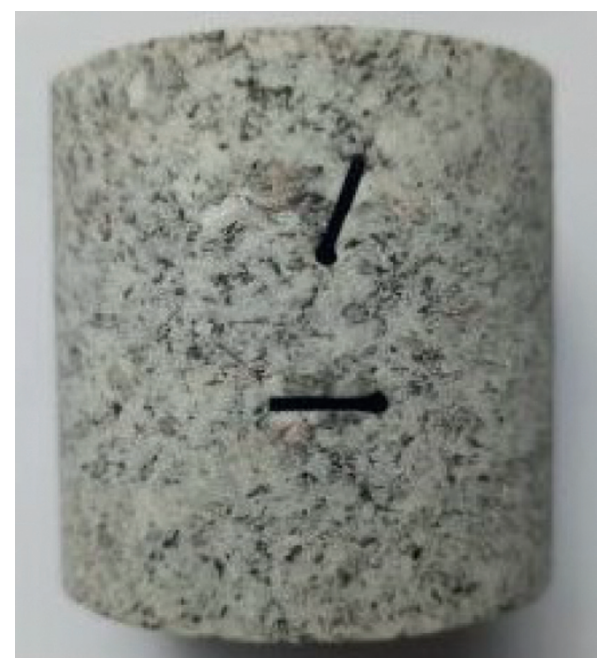

(c)

Figure 3: Preparation of the preflawed granite samples used for the SHPB tests. (a) $\beta=30$, (b) $\beta=50$, and (c) $\beta=70$.

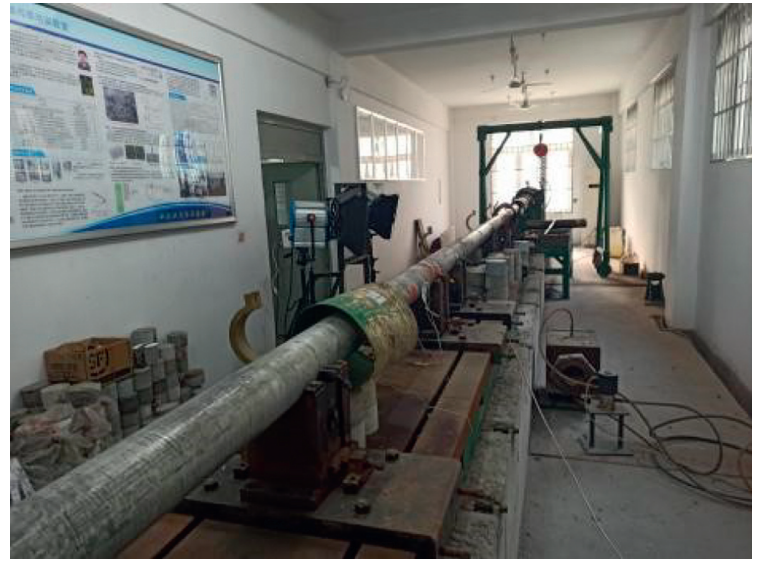

(a)

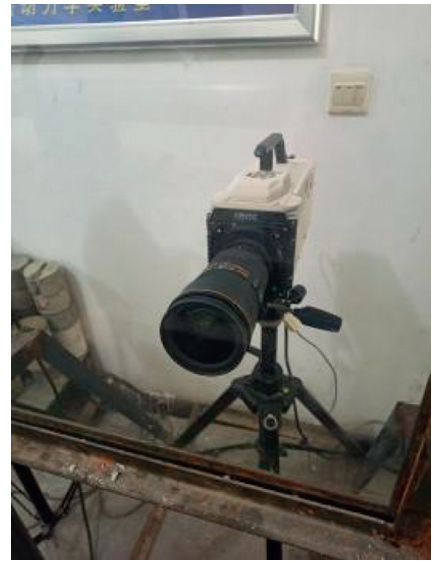

(b)

FIgURE 4: SHPB testing system. (a) Hopkinson compression bar test setup; (b) 30,000-frame high-speed camera. 


$$
\varepsilon_{i}+\varepsilon_{r}=\varepsilon_{t}
$$

Using the data of incident wave $\varepsilon_{i}$ and transmitted wave $\varepsilon_{t}$, we can obtain

$$
\begin{aligned}
& \sigma_{s}=\frac{E A_{0}}{A_{s}} \varepsilon_{t}, \\
& \varepsilon_{s}=\frac{2 C_{0}}{l_{s}} \int_{0}^{t}\left[\varepsilon_{i}-\varepsilon_{t}\right] \mathrm{d} \tau, \\
& \dot{\varepsilon}_{s}=\frac{2 C_{0}}{l_{s}}\left[\varepsilon_{i}-\varepsilon_{t}\right] .
\end{aligned}
$$

The stress, strain, and strain rate curves of the specimen with time are thus obtained.

Equations (2) and (4) are the "three-wave method" and "two-wave method" for measuring the stress-strain relationship at high strain rates in conventional SHPB experiments. Due to the long incident rod in the SHPB experiment, the incident waveform will be distorted to a certain extent during the reflection process, and it is more serious for the large diameter SHPB device, while the material of the specimen is uniform, the distance is short, the filtering effect is good, and the transmission wave dispersion is small, so the incident and transmission waves of the two-wave method are usually used.

According to the law of conservation of energy, the dissipation energy $W_{s}(t)$ of the impact compression experimental specimen is

$$
W_{s}(t)=W_{i}(t)-W_{r}(t)-W_{t}(t),
$$

where $W_{i}(t), W_{r}(t)$, and $W_{t}(t)$ are the incident, reflected, and transmitted wave energies, respectively, and the expressions are as follows:

$$
\begin{aligned}
& W_{i}(t)=E_{0} C_{0} A_{0} \int_{0}^{t} \varepsilon_{i}^{2}(t) \mathrm{d} \tau, \\
& W_{r}(t)=E_{0} C_{0} A_{0} \int_{0}^{t} \varepsilon_{r}^{2}(t) \mathrm{d} \tau, \\
& W_{t}(t)=E_{0} C_{0} A_{0} \int_{0}^{t} \varepsilon_{t}^{2}(t) \mathrm{d} \tau .
\end{aligned}
$$

\section{Test Results}

3.1. Typical Dynamic Stress-Strain Curves. The test data were processed according to the one-wave method [25], and the stress-strain curves were analyzed and plotted after the curve reached stress equilibrium. The dynamic stress-strain curves of rock specimens with different rock bridge angles at different impact air pressures are shown in Figure 5.

The data collected by the SHPB system were processed to obtain the stress-strain curves, as shown in Figure 5. From the dynamic stress-strain curves in Figure 5, it can be seen that the dynamic stress-strain curves can be divided into five stages: pore compacting stage, elastic deformation stage, microfracture stable development stage, microcrack unstable development stage, and post damage stage. The rock material is a natural nonhomogeneous material, and the specimen contains more microcracks in the open state inside, which are gradually closed under the action of lower stresses. When the stress grows to a certain value, the stressstrain curve shows a certain range of elastic growth, and then the specimen produces more and more trace new fractures, and finally in the microcrack nonstable development stage. The sharp increase of new fractures leads to mutual penetration, until the internal structure of the rock is completely destroyed to form a macroscopic fracture surface. The analysis shows that the dynamic stress-strain curves of granite specimens with different bridge angles and strain rates are basically the same.

At different strain rates, the peak stress increases with increasing strain rate, but the increase is smaller and smaller. This is because there is a certain delayed response of the rock under the impact load, and the strength of the rock will increase with the increase of strain rate, tending to the upper limit of strength. For the granite specimens in this work, it is analyzed that the peak strain is positively correlated with the strain rate when the strain rate is from $30 \mathrm{~s}^{-1}$ to $100 \mathrm{~s}^{-1}$. When the strain rate changes to $143.8 \mathrm{~s}^{-1}$, the peak strain corresponding to the peak stress becomes smaller because the impact load is too large and the internal fracture of the rock is damaged before it can be expanded.

In order to investigate the relationship between peak stress and rock bridge angle and strain rate, the peak stresses of granite specimens with different rock bridge angles at different strain rates shown in Table 1 are summarized.

Table 1 lists the peak stresses of granite specimens with different rock bridge angles at various strain rates.

Figure 6 plots the relationship between the peak stress with the angle and strain rate of the tested granite samples. The peak stress increases with increasing strain rate, but the increase is getting smaller because the rock itself responds with a certain delay under the impact load, while the strength of granite increases with increasing strain rate, but there is an upper limit. For the granite specimens in this work, the peak strain is positively correlated with the strain rate; when the strain rate changes to $143.8 \mathrm{~s}^{-1}$, the peak strain corresponding to the peak stress becomes smaller because the impact load is too large and the internal fractures of the granite specimens are damaged before the specimens can be expanded. The peak stress of granite specimens with the same strain rate of the bridge angle of $30^{\circ}$ is the smallest, while the peak stress of granite specimens with the bridge angle of $70^{\circ}$ is the largest, and the peak stress will increase with the increase of the bridge angle. This shows that the effect of the bridge angle on the strength of granite specimens is significant, which is due to the locking effect of the bridge on the interrupted jointed rock body to improve the strength of the rock. In order to describe the relationship between peak stress and strain rate more precisely, so the data of rock bridge angle of $30^{\circ}$ was taken for curve fitting, and the fitting results are shown in Figure 7.

The regression simulation of the relational curve yields the following functional equation between peak stress and strain rate. 


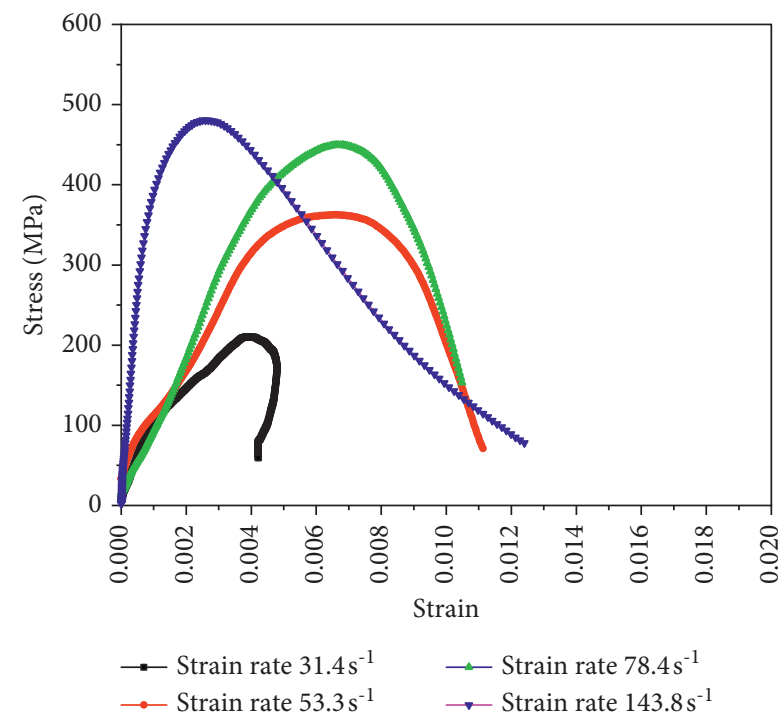

(a)

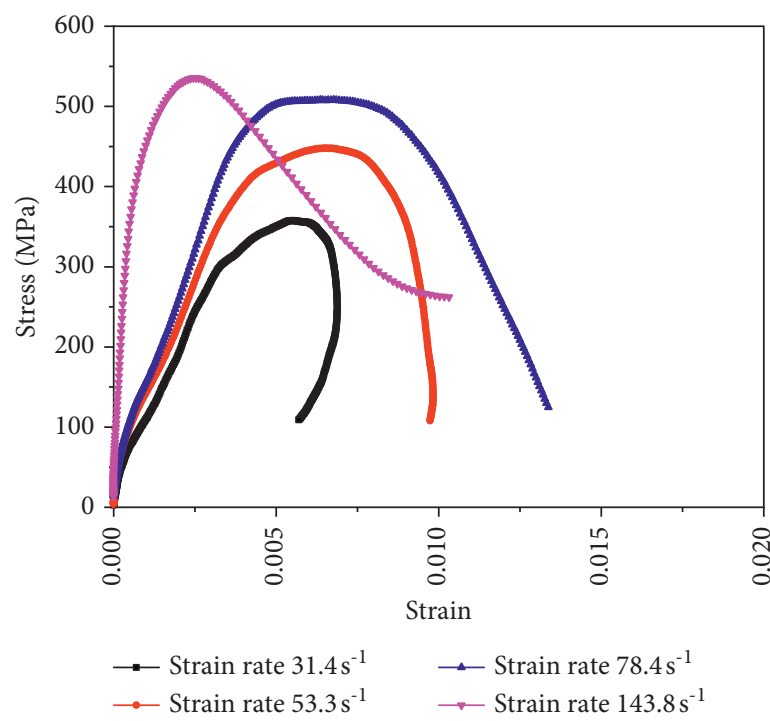

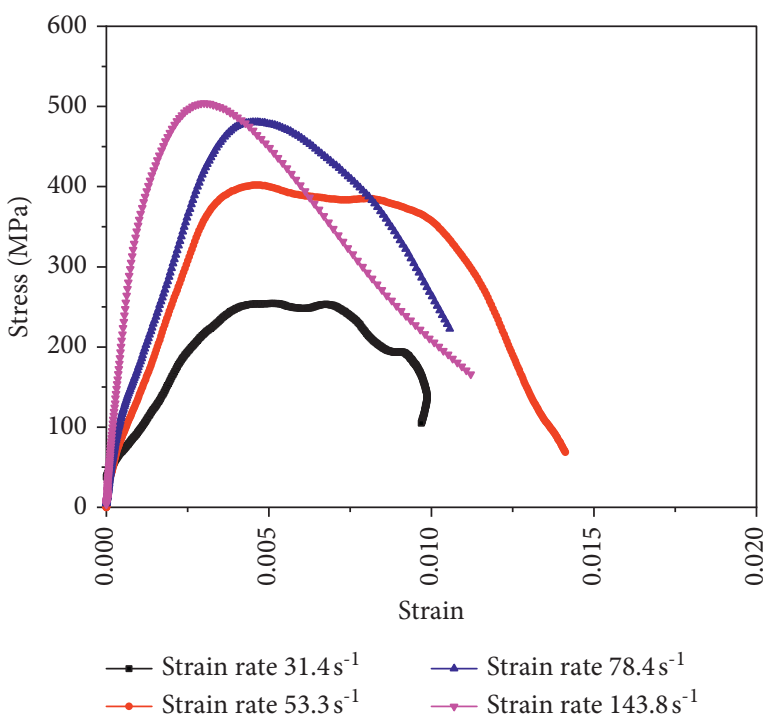

(b)

(c)

Figure 5: Dynamic stress-strain curves of granite specimens with different rock bridge angles at different strain rates. (a) Rock bridge angle of $30^{\circ}$, (b) rock bridge angle of $50^{\circ}$, and (c) rock bridge angle of $70^{\circ}$.

TABLE 1: Summarization of rock peak strength for rock under different strain rates.

\begin{tabular}{lcccc}
\hline Rock bridge angle & $\dot{\varepsilon}=31.4 \mathrm{~s}^{-1}$ & $\dot{\varepsilon}=53.3 \mathrm{~s}^{-1}$ & $\dot{\varepsilon}=78.4 \mathrm{~s}^{-1}$ & $\dot{\varepsilon}=143.8 \mathrm{~s}^{-1}$ \\
\hline $30^{\circ}$ & 210 & 363 & 453 & 480 \\
$50^{\circ}$ & 257 & 404 & 487 & 503 \\
$70^{\circ}$ & 359 & 454 & 512 & 530 \\
\hline
\end{tabular}

$$
\sigma=a-b \cdot c^{\dot{\varepsilon}}
$$

where $\sigma$ is the peak stress, $a=487.24, b=963.09, c=0.96$, and the correlation $R^{2}=0.99659$, indicating obvious correlation.

The value range of this curve strain rate $\varepsilon$ should be greater than $15 \mathrm{~s}^{-1}$, if the strain rate is less than $15 \mathrm{~s}^{-1}$, the peak value is negative, which is not in line with the reality. It can also be concluded that the peak stress of the granite specimen with the rock bridge angle of $30^{\circ}$ increases gradually with the increase of strain rate, but the increase is getting smaller and smaller, and the peak will not exceed $487 \mathrm{MPa}$.

3.2. Energy Conversion Analysis. Assuming that the test system is a closed system and that there is no heat exchange with the outside world during the test. The kinetic energy transferred by compression of the rock near the peak will be 


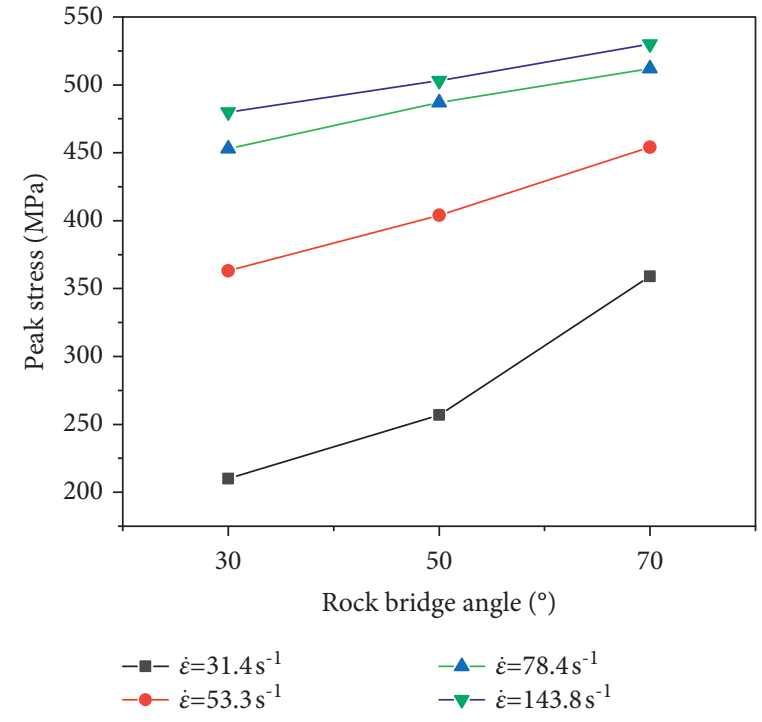

(a)

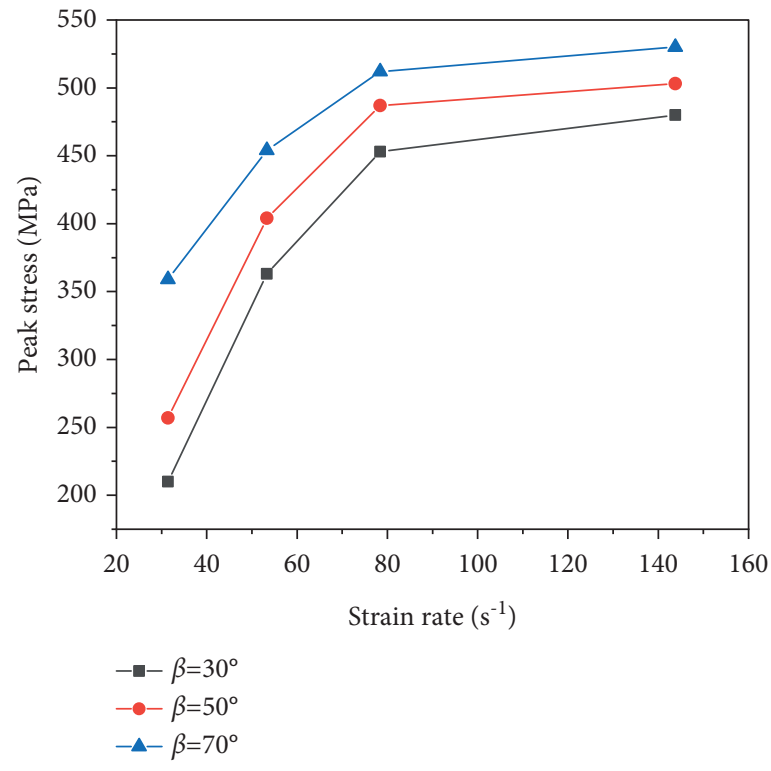

(b)

FIGURE 6: Peak stresses of granite specimens. (a) Variation of peak stress with angle of rock bridge; (b) variation of peak stress with strain rate.

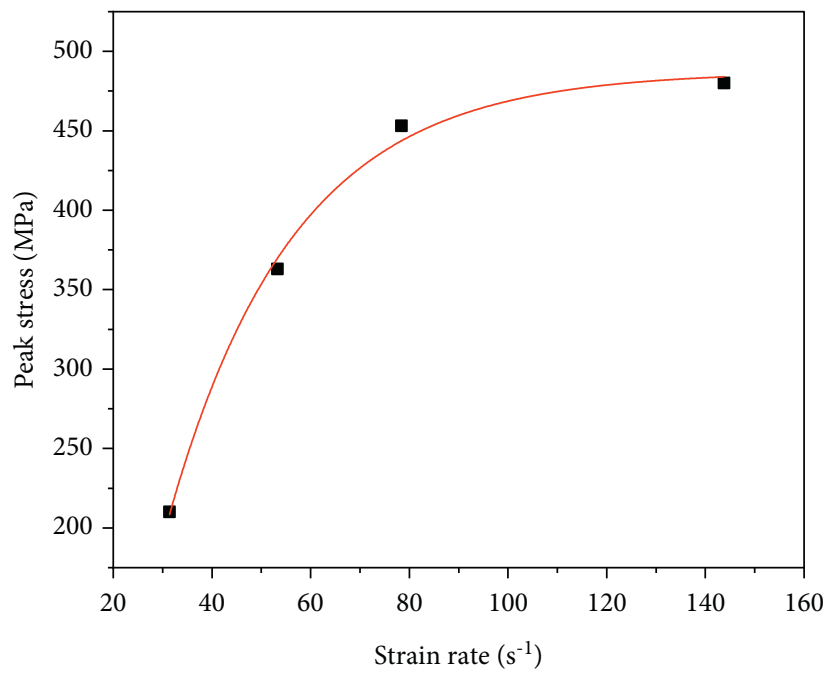

FIGURE 7: Fitting curve of peak strength versus strain rate for granite specimens with rock bridge angle of $30^{\circ}$.

neglected for rock samples under impact loading, and then the total uniaxial axial input strain energy $U$ is obtained under pressure according to the first law of thermodynamics as $[26-28]$

$$
U=U_{d}+U_{e},
$$

where $U_{d}$ is the dissipative strain energy and $U_{e}$ is the releasable elastic strain energy.

The energy evolution curves of the granite samples with different rock bridge angle are plotted in Figures 8-10. The black curve in the figures shows the total energy evolution curve of the granite specimen under the impact load, which divides the energy absorption curve of the total input strain energy of the impact process into four stages. The first stage is the compacting stage, where the impact load compacts the microcracks and pores, and the energy evolution curve is concave upward and rises slowly. The second stage is the elastic deformation stage. The absorbed energy increases rapidly, and the elastic strain energy increases accordingly, and the energy evolution curve is approximately linear. The third stage is the yielding stage. The specimen produces new cracks and the existing cracks further evolve, and the energy evolution curve deviates from a straight line, but the specimen still has a certain load-bearing capacity. The fourth stage is the damage stage, the energy absorbed by the specimen no longer increases, and the energy evolution curve tends to be smooth. 


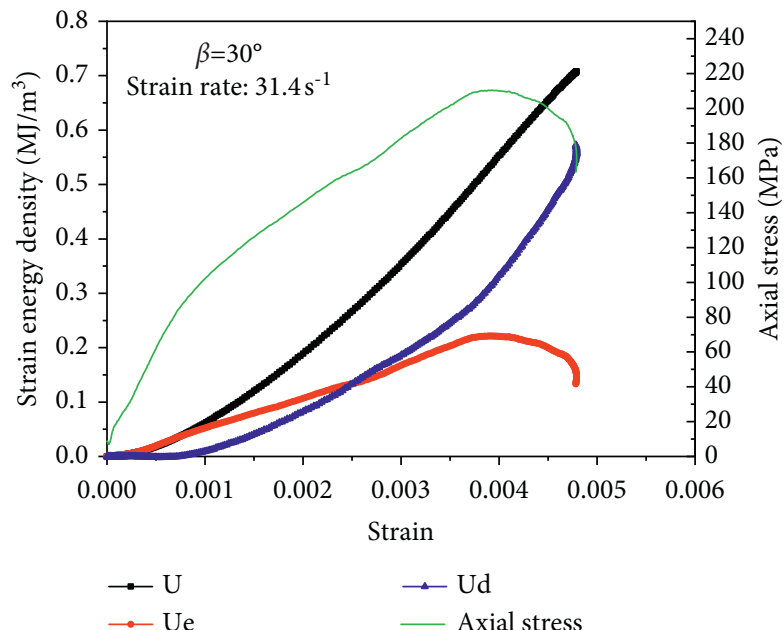

(a)

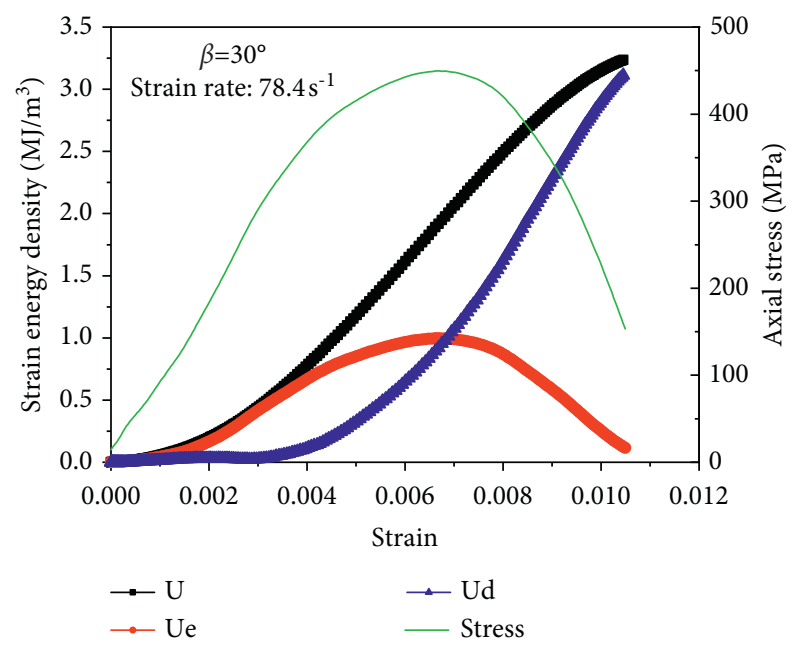

(c)

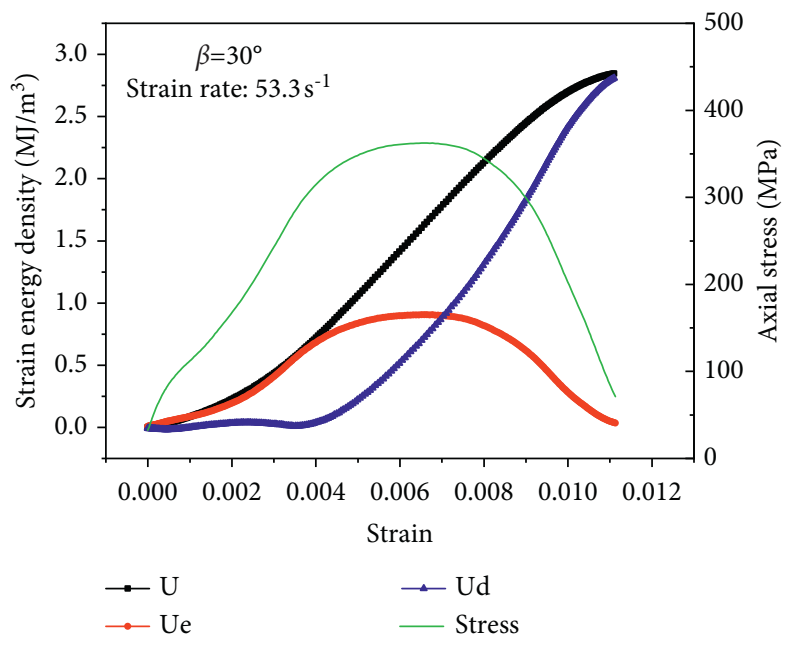

(b)

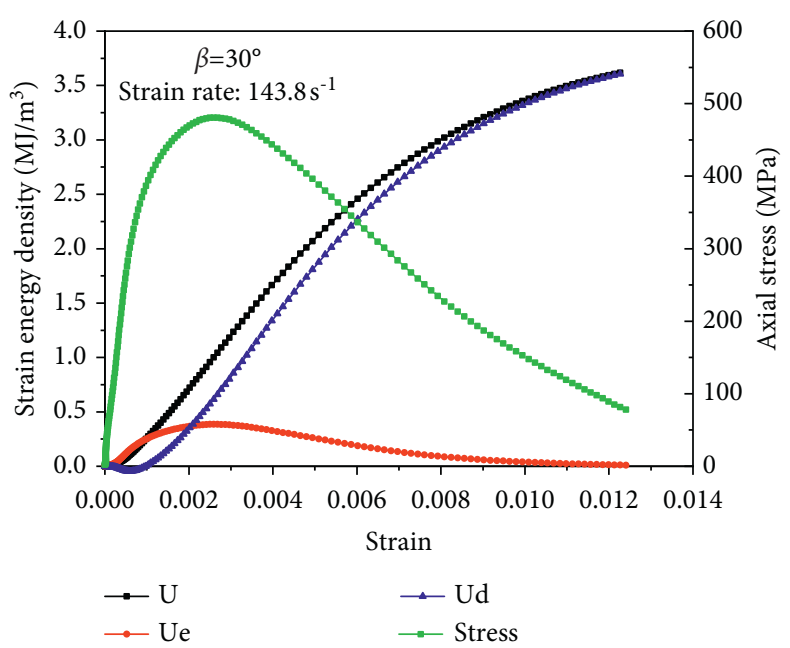

(d)

FIGURE 8: Strain energy density versus axial strain for rock with $30^{\circ}$ rock bridge angle subjected to different loading rates.

The energy evolution curves of the dissipated strain energy $U_{d}$ and the elastic strain energy $U_{e}$ of the rock specimen at different stages also show different energy evolution characteristics. During the compression-density stage, both the releasable elastic strain energy and the dissipated strain energy are accumulated. At the elastic deformation stage, the releasable elastic strain energy is continuously accumulated and the dissipated energy is almost not increased. At the yielding stage, the increase rate of the releasable elastic strain energy becomes slower and the energy dissipation rate becomes faster. At the damage stage, the elastic strain energy is released drastically and the energy dissipation is drastic.

Under the action of impact loading, the total input strain energy of the rock specimen gradually increases, while the input strain energy is converted into releasable elastic strain energy and stored in the rock specimen during the elastic phase of the stress-strain curve. The stored elastic strain energy reaches its maximum value when the peak stress is reached in the stress-strain curve, and the elastic strain energy is finally released with the destruction of the rock specimen. During the whole loading process, the dissipated strain energy is gradually increased, which is due to the friction of microdefect closure, microcrack expansion, and relative misalignment of the fracture surface inside the rock specimen, the granite specimen produces energy dissipation, and finally leads to the loss of cohesion of the rock.

From Figure 11(a), it is shown that the total input strain energy increases with the increase of strain rate. As can be also seen from Figure 11(b), when the strain rate is at $30 \mathrm{~s}^{-1} \sim 80 \mathrm{~s}^{-1}$, the peak releasable elastic strain energy increases gradually with the increase of strain rate. When the strain rate reaches $143.8 \mathrm{~s}^{-1}$, the cracks inside the granite specimen are destroyed without expanding in a short time because the strain rate is too large, so the elastic strain energy is also less during the destruction process and is released quickly. The peak releasable elastic strain energy at a rate of $143.8 \mathrm{~s}^{-1}$ decreases sharply. With the increase of energy input, the energy dissipation also increases and the degree of rock damage becomes more severe, and it is also found that 


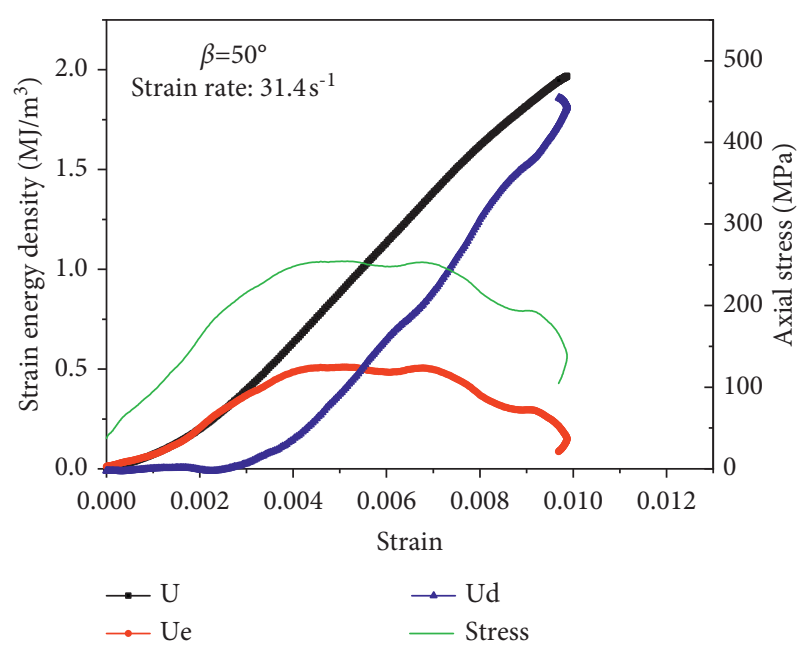

(a)

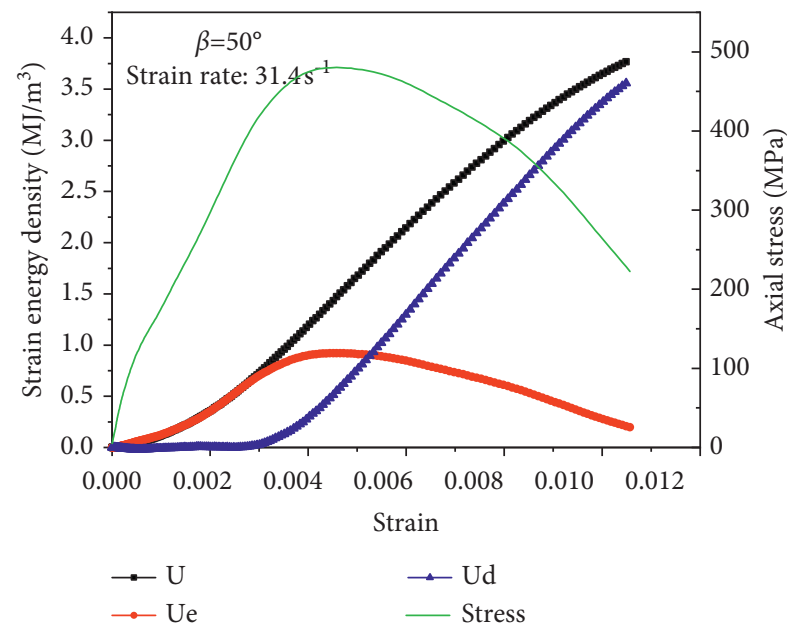

(c)

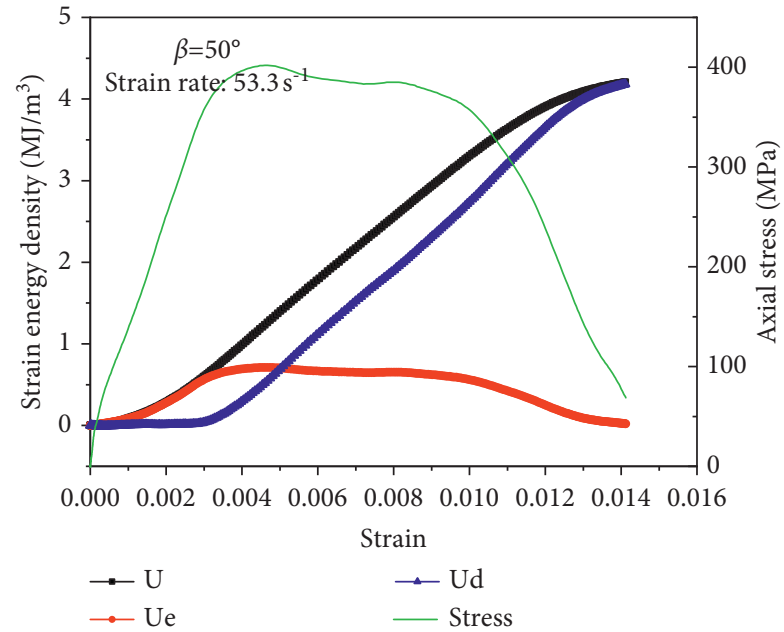

(b)

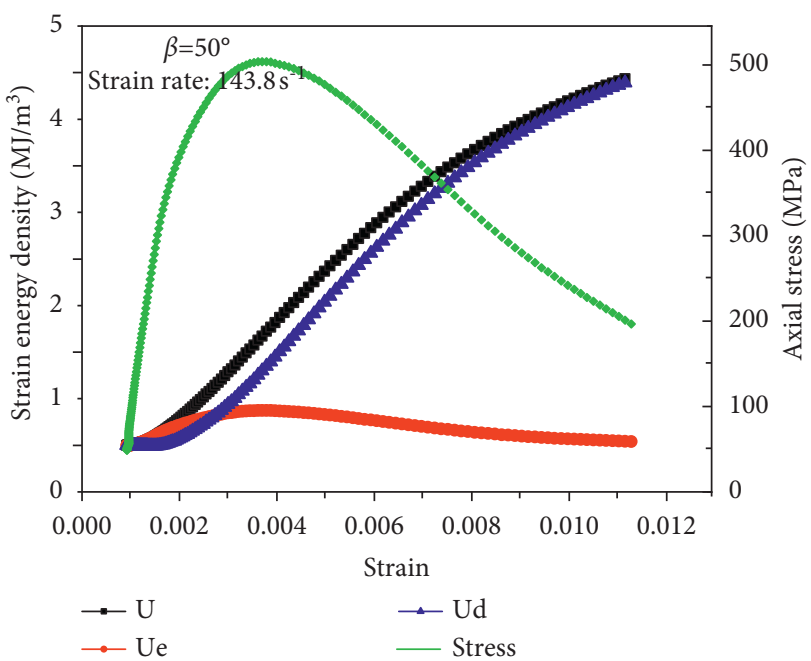

(d)

FIGURE 9: Strain energy density versus axial strain for rock with $50^{\circ}$ rock bridge angle subjected to different loading rates.

the total input strain energy increases with the increase of rock bridge angle. From Figure 11(c), it can be seen that the dissipated energy gradually increases with increasing strain rate.

3.3. Dynamic Fracture Evolution Visualization. In order to obtain the dynamic rupture process of granite specimens under impact loading, a high-speed camera was used to record the crack expansion process of rock specimens, so as to analyze the crack expansion process of rock specimens under different rock bridge angles and different strain rates. The fracture process for the tested granite samples with different approach angle is shown in Figure 12. It can be seen that both the strain rate and the approach angle impact the propagation path of cracks. In addition, crack density increases with increasing strain rate.

The fracture process of the granite specimen shown in Figure 12 reveals the dynamic fracture evolution process of the locked rock. Under the impact loading, the cracks first start to expand from the tip ends of the two prefabricated fractures. When the cracks at the tip ends start to expand, the two prefabricated fractures gradually compact and close, and the width of the prefabricated fractures decreases significantly. As the cracks at the tip ends of the prefabricated fractures expand to a certain degree, secondary fractures start to appear. With the increase of the applied loads, the width of the secondary fractures gradually increases, and finally the fractures penetrate, the width of the fractures increases abruptly, and the rock specimen damages. Comparing the damage process of rock specimens under different rock bridge angles and different strain rates, it is found that the crack propagation path and network are complex for a rock with a larger the rock bridge angle. With the increase of the strain rate, the number and width of cracks both increase, which is because the ductility of rock specimens increases with the increase of strain rate. However, there exists a specific value of strain rate, and when the strain rate exceeds this value, the cracks inside the granite specimen will be damaged because it is too late to expand in a short time. 


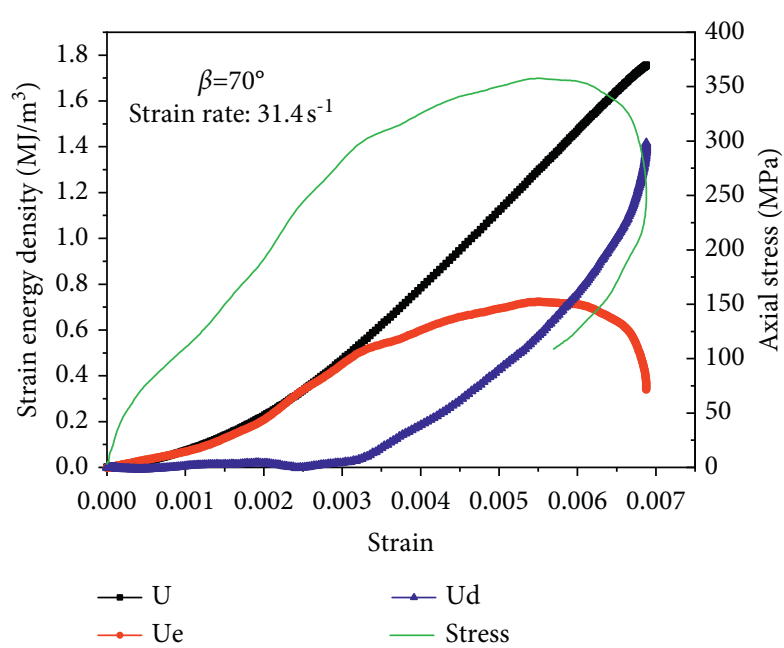

(a)

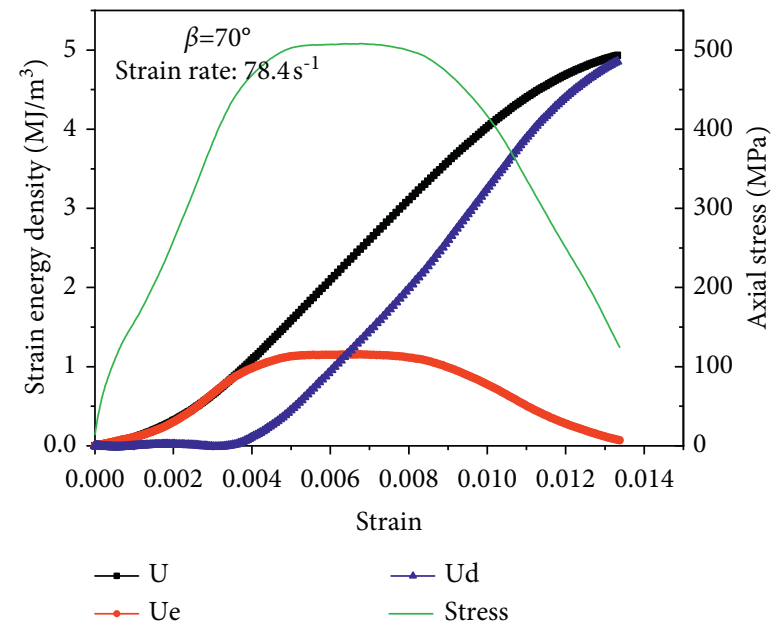

(c)

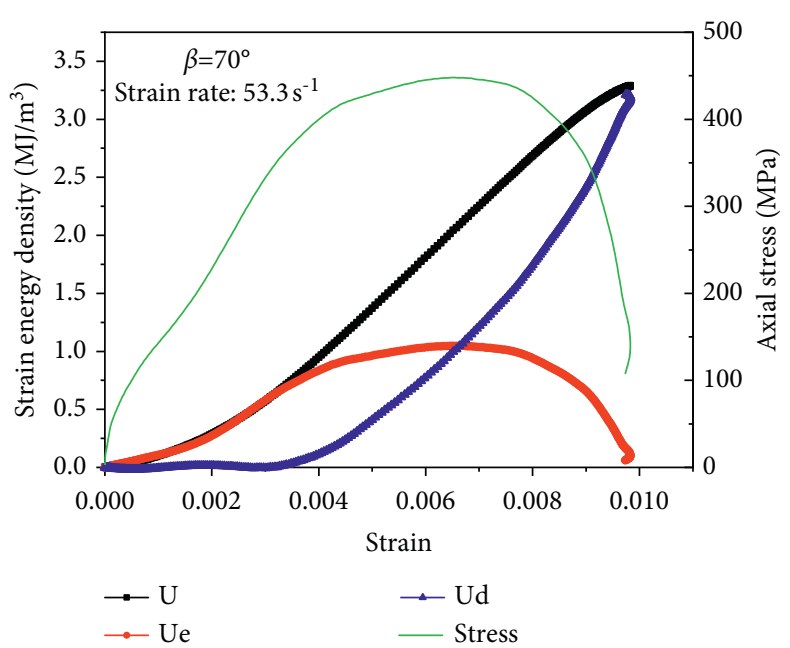

(b)

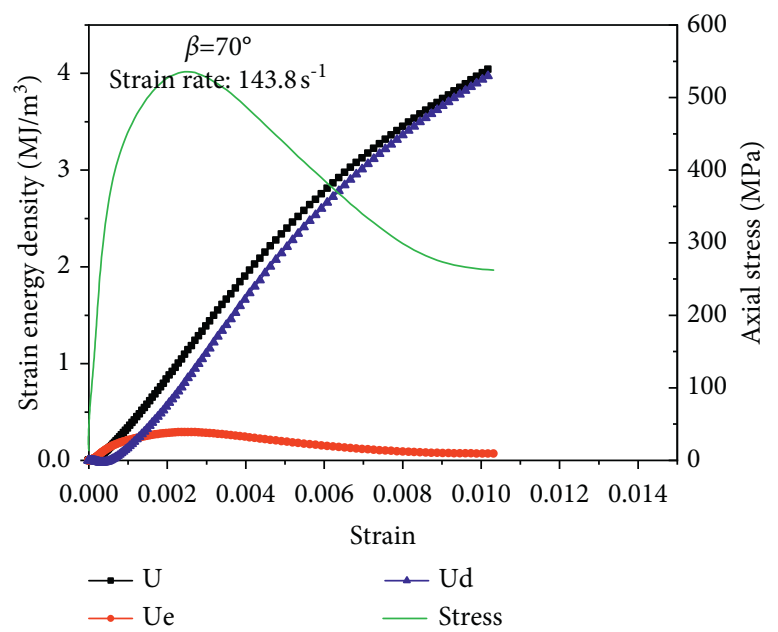

(d)

FIGURE 10: Strain energy density versus axial strain for rock with $70^{\circ}$ rock bridge angle subjected to different loading rates.

When the strain rate of the granite specimen is relatively low, the damage of the rock has the typical characteristics of axial splitting damage. The XRD analysis shows that the granite specimens are rich in brittle minerals such as quartz and feldspar, which are highly susceptible to brittle fracture under impact loading. With the increase of strain rate, the damage mode of granite specimens changed from axial splitting to crushing. Cracks first appear along the quartzquartz or quartz-feldspar boundaries, and with the increase of external load, the cracks in the quartz grains expand rapidly, while the separation of the deconstruction surface is the main damage mode of the black mica.
The locked segments in the granite specimens are marked with white ellipses, and it is found that the cracks at the locked segments are all through when the rocks are in the damage stage. For the rock specimens at the same strain rate, the effect of the rock bridge angle on the crack extension is also significant. A comparison of the crack extension process by the strain rate of $31.4 \mathrm{~s}^{-1}$ in Figures 12(a) 12(c) shows that the width of the crack as well as the damage of the final rock specimen increases sharply with the increase of the rock bridge angle, which also indicates that the rock locking section has a controlling effect on the crack extension. 


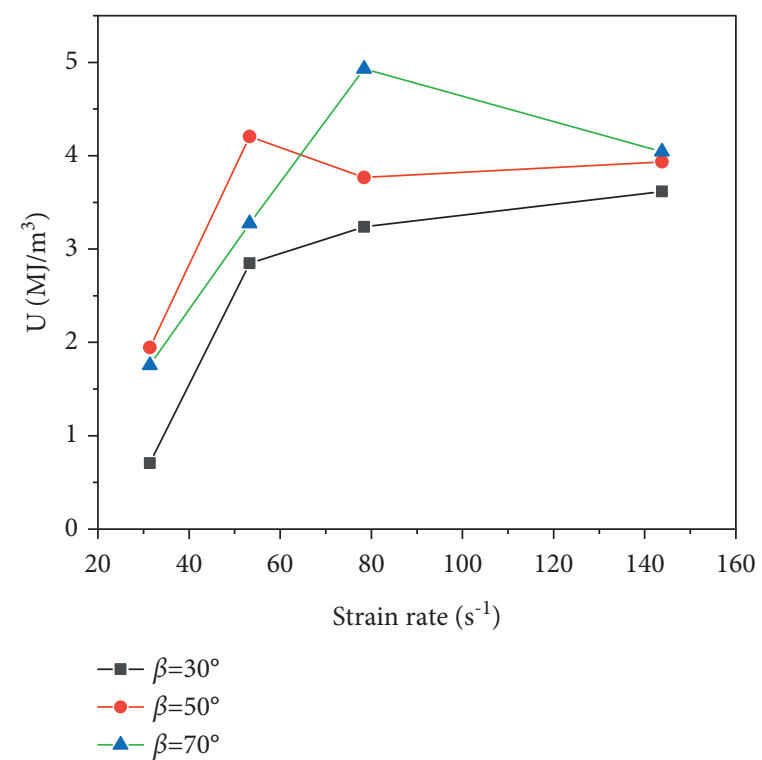

(a)

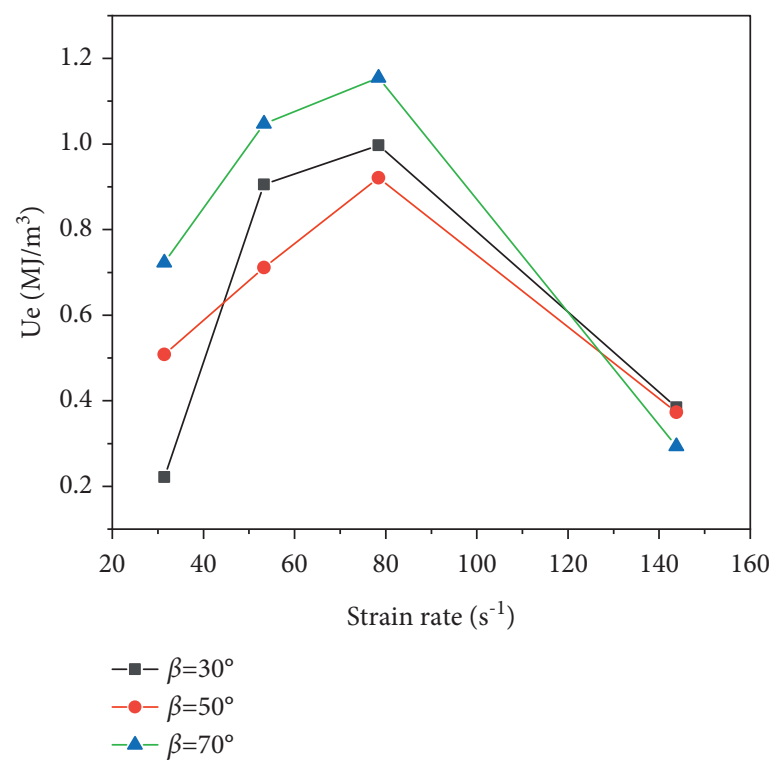

(b)

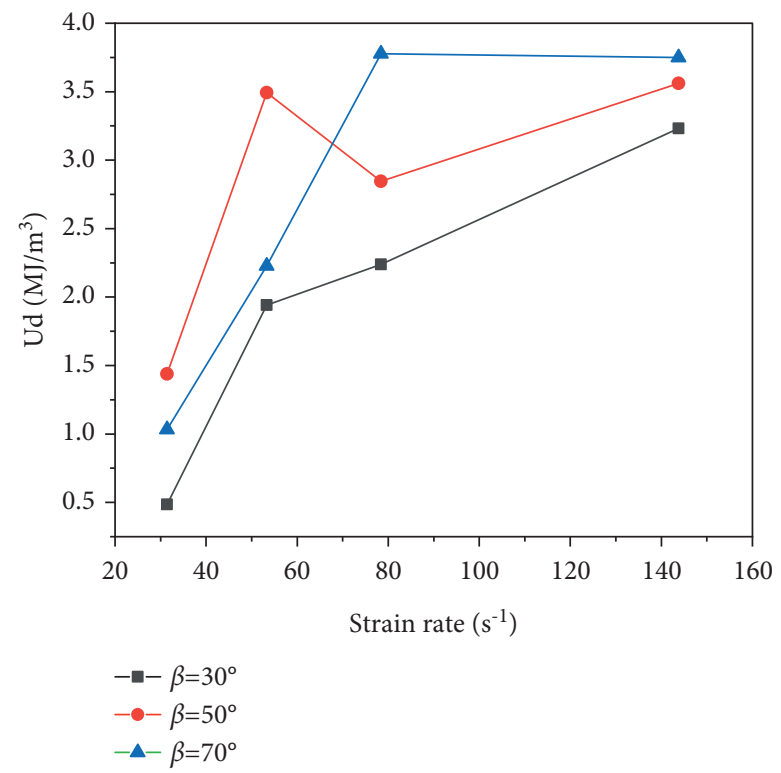

(c)

FIGURE 11: Plots of the relationship between the strain density against strain rate. (a) $U$; (b) $U_{e}$; (c) $U_{d}$. 


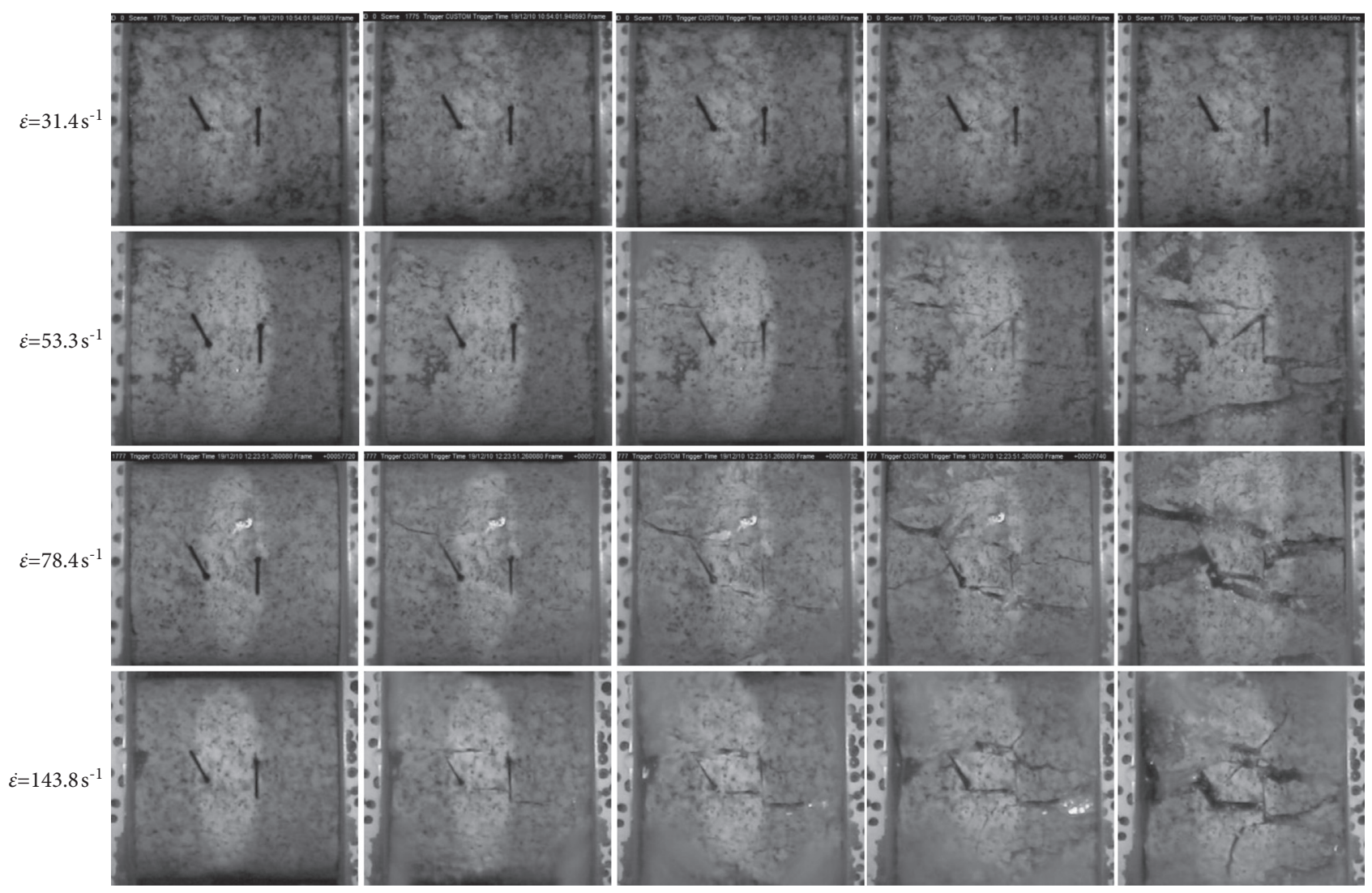

(a)

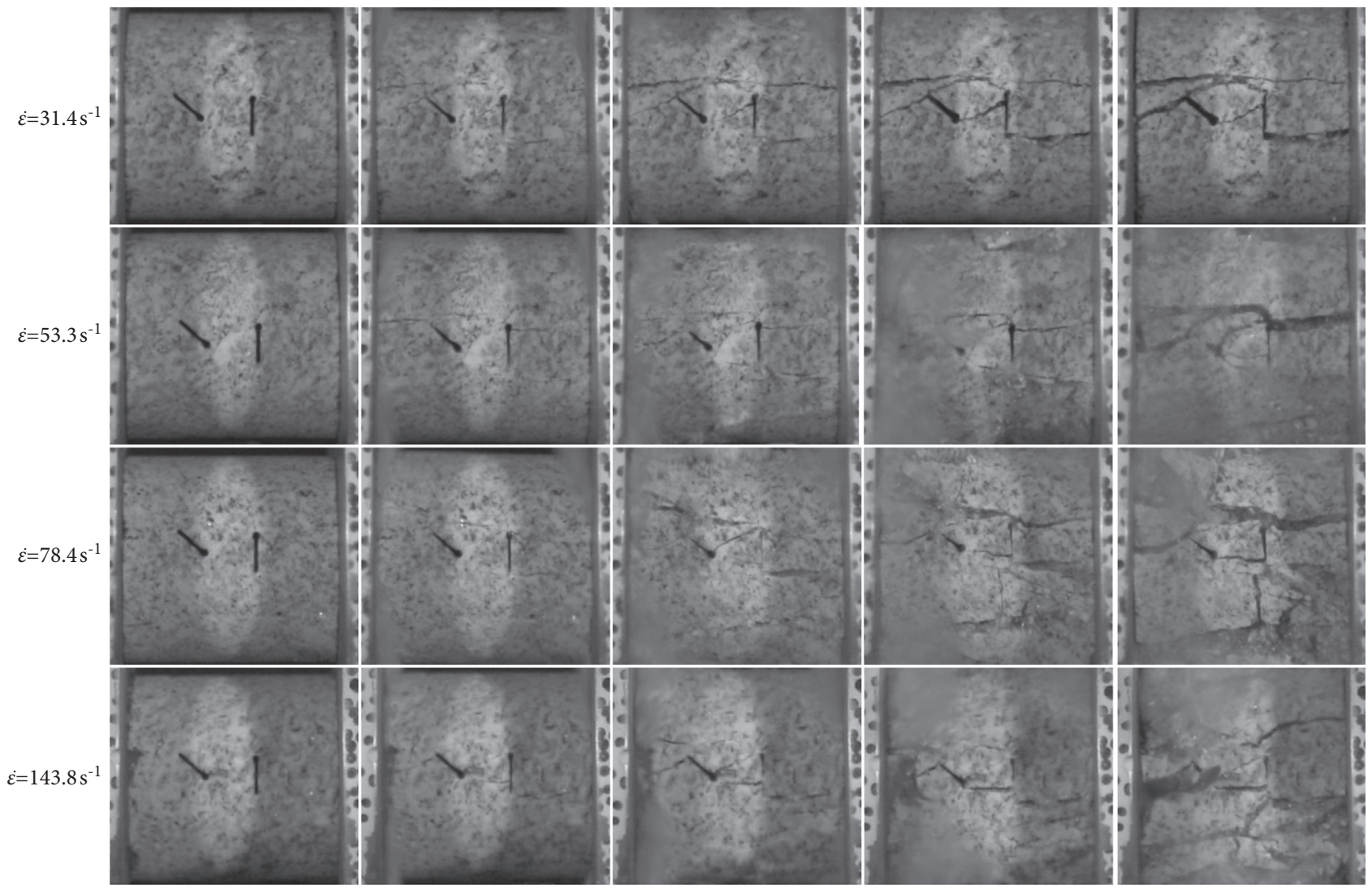

(b)

Figure 12: Continued. 

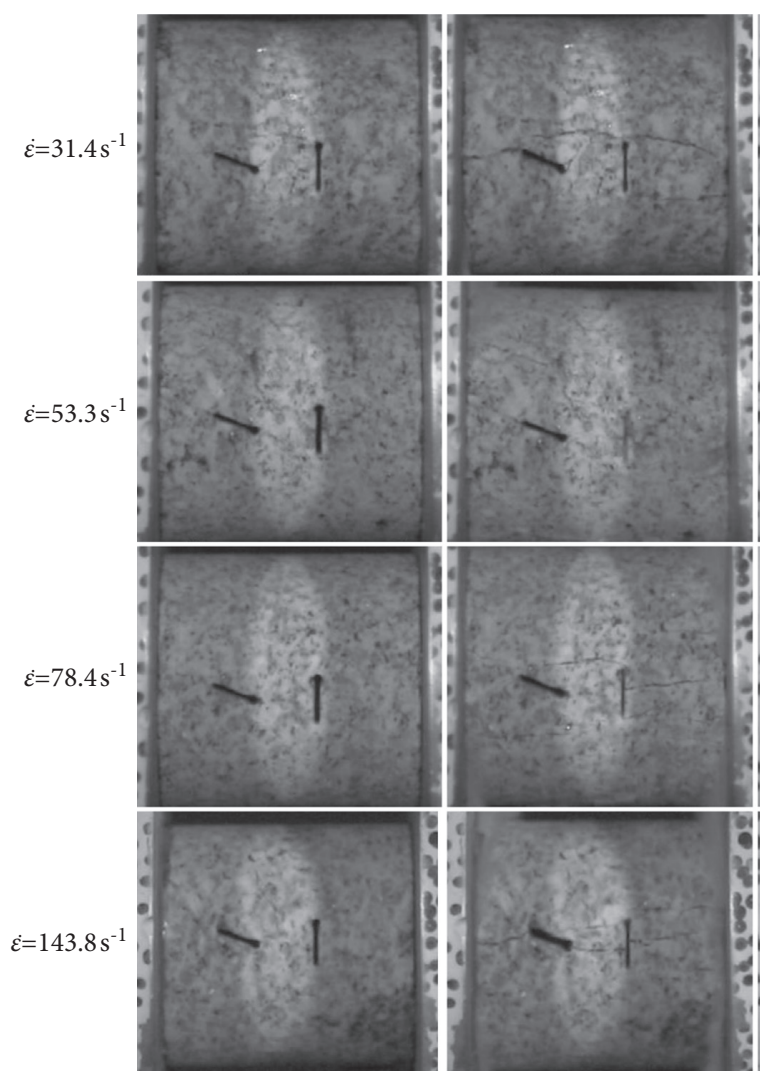
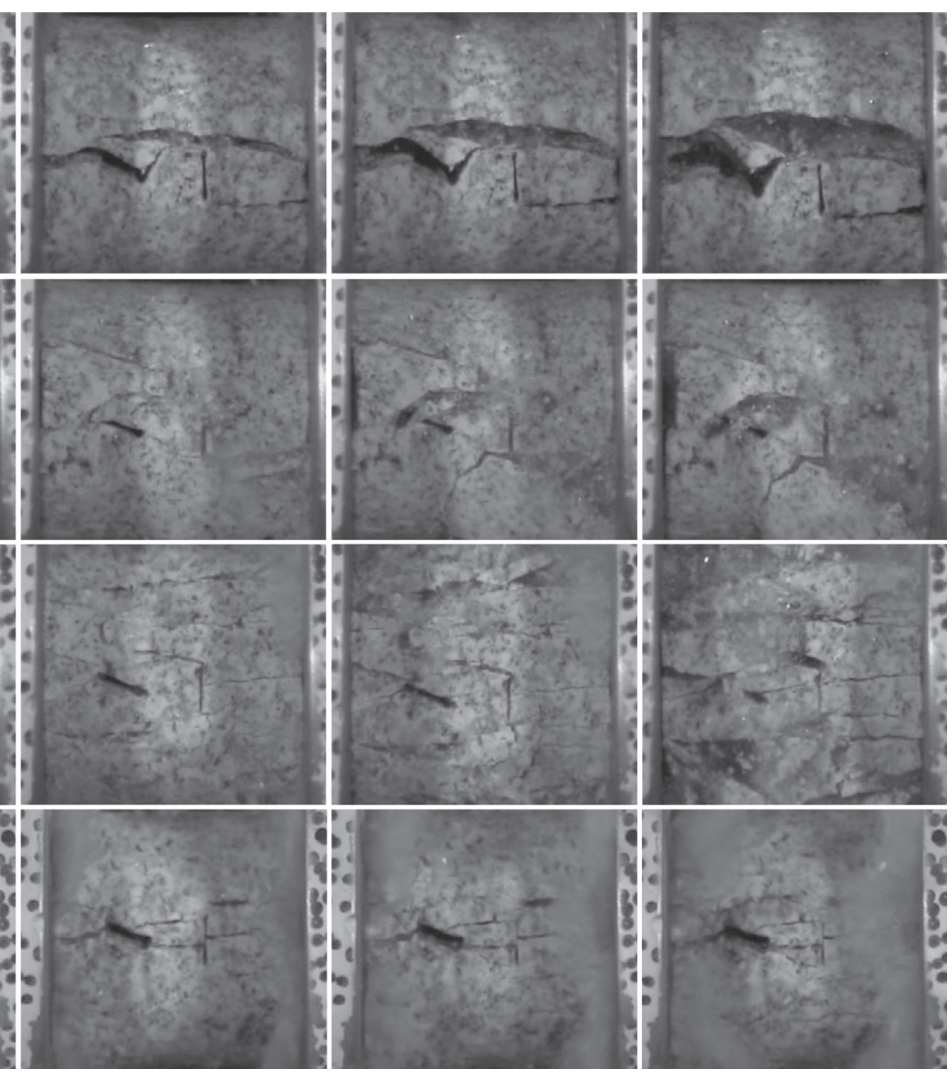

(c)

FIGURE 12: Description of crack propagation using high-speed camera for rock specimens at different strain rates: (a) rock bridge angle of $30^{\circ}$, (b) rock bridge angle of $50^{\circ}$, and (c) rock bridge angle of $70^{\circ}$.

\section{Conclusions}

In this work, granite specimens with prefabricated different rock bridge angles were dynamically loaded using the SHPB loading method to investigate the stress-strain and energy as well as their dynamic rupture processes. Based on the above analysis, the main conclusions are summarized as follows:

(1) The peak stress of granite will increase with the increase of rock bridge angle. This is because the locking effect of the rock bridge on the interrupted joints increases the strength of the rock; the peak stress of granite also increases with the increase of strain rate, but the increase is smaller and smaller under the action of impact loading.

(2) The peak total strain energy increases with the increase of rock bridge angle and strain rate. The input energy is mainly transformed into elastic strain energy in the elastic deformation stage and all of it is released when the specimen is damaged. While the dissipated strain energy gradually increases with the increase of the energy input, and its increasing rate becomes faster and faster.

(3) The crack propagation path is influenced by both the rock bridge angle and strain rate. The larger the rock bridge angle is, the more obvious the crack expansion is and the more severe the damage of the rock when the crack propagation. With the increase of the strain rate, the number and width of cracks also increase. The locking section has a controlling effect on the damage of the rock, and the rock will be damaged only when the crack penetrates at the locking section.

\section{Data Availability}

The experimental data used to support the findings of this study are included within the article.

\section{Conflicts of Interest}

The authors declare no conflicts of interest.

\section{Acknowledgments}

This research was financially supported by the China Coal Technology Engineering Group Innovation Fundation (Grant 2018-2-ZD007), Beijing Science and Technology Fundation (Z181100005118012), and the National Natural Science Foundation of China (Grant 41972259). 


\section{References}

[1] L. A. M. Camones, E. d. A. Vargas, R. P. De Figueiredo, and R. Q. Velloso, "Application of the discrete element method for modeling of rock crack propagation and coalescence in the step-path failure mechanism," Engineering Geology, vol. 153, pp. 80-94, 2013.

[2] Q. Wang, M. He, S. Li et al., "Comparative study of model tests on automatically formed roadway and gob-side entry driving in deep coal mines," International Journal of Mining Science and Technology, vol. 31, 2021.

[3] R. Yang, Y. Xu, P. Chen, and J. Wang, "Experimental study on dynamic mechanics and energy evolution of rubber concrete under cyclic impact loading and dynamic splitting tension," Construction and Building Materials, vol. 262, Article ID 120071, 2020.

[4] H. Chen and L. Xue, "Numerical investigation on progressive fracture behaviours of macroscopic heterogeneous rock bridge," European Journal of Environmental and Civil Engineering, vol. 24, no. 5, pp. 603-619, 2020.

[5] Z. Tao, Y. Shu, X. Yang, Y. Peng, Q. Chen, and H. Zhang, "Physical model test study on shear strength characteristics of slope sliding surface in Nanfen open-pit mine," International Journal of Mining Science and Technology, vol. 30, no. 3, pp. 421-429, 2020.

[6] W. Wan, J. Liu, Y. Zhao, and X. Fan, "The effects of the rock bridge ligament angle and the confinement on crack coalescence in rock bridges: an experimental study and discrete element method," Comptes Rendus Mecanique, vol. 347, no. 6, pp. 490-503, 2019.

[7] Q. Wang, Y. Wang, M. He et al., "Experimental research and application of automatically formed roadway without advance tunneling," Tunnelling and Underground Space Technology, vol. 114, Article ID 103999, 2021.

[8] H. Wang, Y. Li, S. Li, Q. Zhang, and J. Liu, "An elasto-plastic damage constitutive model for jointed rock mass with an application," Geomechanics and Engineering, vol. 11, no. 1, pp. 77-94, 2016.

[9] Q. Yin, J. Wu, C. Zhu, M. He, Q. Meng, and H. Jing, "Shear mechanical responses of sandstone exposed to high temperature under constant normal stiffness boundary conditions," Geomechanics and Geophysics for Geo-Energy and Geo-Resources, vol. 7, no. 2, pp. 1-17, 2021.

[10] Y. Wang, B. Zhang, B. Li, and C. H. Li, "A strain-based fatigue damage model for naturally fractured marble subjected to freeze-thaw and uniaxial cyclic loads," International Journal of Damage Mechanics, vol. 30, no. 9, pp. 1305-1323, 2021.

[11] B. Cerfontaine and F. Collin, "Cyclic and fatigue behaviour of rock materials: review, interpretation and research perspectives," Rock Mechanics and Rock Engineering, vol. 51, no. 2, pp. 391-414, 2018.

[12] Y. Wang, Y. F. Yi, C. H. Li, and J. Q. Han, “Anisotropic fracture and energy characteristics of a Tibet marble exposed to multi-level constant-amplitude (MLCA) cyclic loads: a lab-scale testing," Engineering Fracture Mechanics, vol. 244, Article ID 107550, 2021.

[13] Y. Wang, W. K. Feng, H. J. Wang, C. H. Li, and Z. Q. Hou, "Rock bridge fracturing characteristics in granite induced by freeze-thaw and uniaxial deformation revealed by AE monitoring and post-test CT scanning," Cold Regions Science and Technology, vol. 177, Article ID 103115, 2020.

[14] R. H. C. Wong, K. T. Chau, C. A. Tang, and P. Lin, "Analysis of crack coalescence in rock-like materials containing three flaws-part I: experimental approach," International Journal of
Rock Mechanics and Mining Sciences, vol. 38, no. 7, pp. 909-924, 2001.

[15] J. T. Gomez, A. Shukla, and A. Sharma, "Static and dynamic behavior of concrete and granite in tension with damage," Theoretical and Applied Fracture Mechanics, vol. 36, no. 1, pp. 37-49, 2001.

[16] Q. B. Zhang and J. Zhao, "Determination of mechanical properties and full-field strain measurements of rock material under dynamic loads," International Journal of Rock Mechanics and Mining Sciences, vol. 60, pp. 423-439, 2013.

[17] X. Li, Z. Zhou, T.-S. Lok, L. Hong, and T. Yin, "Innovative testing technique of rock subjected to coupled static and dynamic loads," International Journal of Rock Mechanics and Mining Sciences, vol. 45, no. 5, pp. 739-748, 2008.

[18] F. Gong, H. Jia, Z. Zhang, J. Hu, and S. Luo, "Energy dissipation and particle size distribution of granite under different incident energies in SHPB compression tests," Shock and Vibration, vol. 2020, Article ID 8899355, 2020.

[19] R. Yang, W. Li, and Z. Yue, "Comparative study on dynamic mechanical properties and energy dissipation of rocks under impact loads," Shock and Vibration, vol. 2020, Article ID 8865099, 2020.

[20] L. Wang, Y. Qin, H. Jia, H. Su, and S. Chen, "Study on mechanical properties and energy dissipation of frozen sandstone under shock loading," Shock and Vibration, vol. 2020, Article ID 8893128, 2020.

[21] R. Ulusay, The ISRM Suggested Methods for Rock Characterization, Testing and Monitoring: 2007-2014, Springer International Publishing, Berlin, Germany, 2015.

[22] S. Mishra, T. Chakraborty, and V. Matsagar, "Dynamic characterization of himalayan quartzite using SHPB," in Proceedings of the ISRM European Rock Mechanics Symposium-EUROCK 2017, Ostrava, Czech Republic, June 2017.

[23] X. Li, K. Peng, J. Peng, and D. Hou, "Experimental investigation of cyclic wetting-drying effect on mechanical behavior of a medium-grained sandstone," Engineering Geology, vol. 293, Article ID 106335, 2021.

[24] J. C. Li, L. F. Rong, H. B. Li, and S. N. Hong, "An SHPB test study on stress wave energy attenuation in jointed rock masses," Rock Mechanics and Rock Engineering, vol. 52, no. 2, pp. 403-420, 2019.

[25] M. Wang, F. Wang, Z. Zhu, Y. Dong, M. Mousavi Nezhad, and L. Zhou, "Modelling of crack propagation in rocks under SHPB impacts using a damage method," Fatigue and Fracture of Engineering Materials and Structures, vol. 42, no. 8, pp. 1699-1710, 2019.

[26] Y. Wang, H. Meng, and D. Long, "Experimental investigation of fatigue crack propagation in interbedded marble under multilevel cyclic uniaxial compressive loads," Fatigue and Fracture of Engineering Materials and Structures, vol. 44, no. 4, pp. 933-951, 2021.

[27] Y. Wang, W. K. Feng, R. L. Hu, and C. H. Li, "Fracture evolution and energy characteristics during marble failure under triaxial fatigue cyclic and confining pressure unloading (FC-CPU) conditions," Rock Mechanics and Rock Engineering, vol. 54, no. 2, pp. 799-818, 2021.

[28] H. Xie, L. Li, Y. Ju, R. Peng, and Y. Yang, "Energy analysis for damage and catastrophic failure of rocks," Science China Technological Sciences, vol. 54, no. 1, pp. 199-209, 2011.

[29] Z. Bin, B. I. Teng-Fei, and Y. U. Miao, "Study on the mechanical property and failure model of the granite rock under dynamic loadings," Applied Mechanics and Materials, vol. 744-746, 2014. 